\title{
XXI. On the solubility of certain metallic oxides and salts in muriate and nitrate of ammonia
}

\section{R.H. Brett Esq. F.L.S.}

To cite this article: R.H. Brett Esq. F.L.S. (1837) XXI. On the solubility of certain metallic oxides and salts in muriate and nitrate of ammonia, Philosophical Magazine Series 3, 10:59, 95-100, DOI: $10.1080 / 14786443708649087$

To link to this article: http://dx.doi.org/10.1080/14786443708649087

册 Published online: 01 Jun 2009.

Submit your article to this journal $\sqsubset \pi$

ЏII Article views: 2

Q View related articles $\sqsubset$ 
not feel less inclined now, than when I made and published it, to regard it as unfavourable to the existence of the supposed general law. The differences between this experiment and that of Dr. Faraday on fused periodide of mercury, are, that in the latter the conduction is stated to be feeble, and no signs of decomposition are visible; whilst in the former the conduction is so marked as to impress the mind with the idea that decomposition by the electric current is going forward. The signs of decomposition are obvious, although undoubtedly in part at least due to heat; and the relative number of the constituent atoms of the substance acted upon are much more unequal. Various other considerations are hostile to the general law referred to, some of which are stated in the above memoir*.

In the hope that you may find a corner for the preceding observations, I remain, Gentlemen,

$$
\text { Edinburgh, Nov. 28, 1836. Your very faithful Servant, }
$$

XXI. On the Solubility of certain Metullic Oxides and Salts in Muriate and Nitrate of Ammonia. By R. H. BretT, Esq., F.L.S.†

FROM a notice contained in the Supplement to the December Number of the Philosophical Magazine, (vol. ix. p. 540), of some experiments of M. Vogel on the solubility of the earthy carbonates in muriate of ammonia, corroborated by some experiments on that subject performed by Mr. J.D. Smith, I have been induced to extend the inquiry, for the purpose of ascertaining whether the same salt, as well as the nitrate of ammonia, exerted any solvent action over certain earthy and alkaline salts, which are either insoluble or very sparingly soluble in water, and how far this solvent power extended to the metallic oxides (more ordinarily met with) and their salts insoluble in water. The following are the results:

Salts of Lime. - 1. The carbonate and phosphate readily dissolve in cold solutions of the muriate of ammonia as well as the nitrate, the earthy salts being recently precipitated.

* The volume of the Edinburgh Transactions to which the above memoir belongs lias only now come out, but besides the above-mentioned distribution of the printed memoir, the Society's abstract of the paper referred to was published a year and a half ago, and in it the experiment on fused iodic acid is particularly described. A different abstract appeared in Professor Jameson's Journal (July 1835), in which the other topics of the paper were treated at greater length, whilst those above referred to were for the sake of brevity omitted.

+ Communicated by the Author. 
2. The recently precipitated sulphate dissolves even in the cold, less speedily, however, and perhaps less completely than the carbonate or phosphate.

3. The borate and tartrate dissolve even in the cold.

4. The oxalate does not appear to dissolve either in the hot or cold solution.

The nitrate of ammonia acts much in the same way as the muriate, and a portion of these calcareous salts is retained in the solution of the ammoniacal salts, even after the fluid has been at rest for some time.

Barytic Salts. - 1. The carbonate, phosphate, and oxalate undergo solution in a cold solution of muriate of ammonia.

2. The sulphate does not dissolve.

3. The borate and tartrate undergo solution in the cold salt. A solution of nitrate of ammonia appears to dissolve less of the phosphate of baryta than the muriate of ammonia: it acts much in the same way towards the other barytic salts.

Strontian Salts.-1. The carbonate and phosphate are easily dissolved in a cold solution of muriate of ammonia.

2. The oxalate dissolves in a hot solution of the ammoniacal salt.

3. The sulphate does not undergo solution.

4. The borate and tartrate readily dissolve.

The solution of nitrate of ammonia appears to exert a greater solvent action over the oxalate of strontia than the muriate of ammonia does; in other respects it does not differ from the latter salt.

Magnesian Salts.-1. The phosphate of magnesia and ammoniaco-magnesian phosphate dissolve in a hot solution of muriate of ammonia.

2. The carbonate and tartrate dissolve in a solution of muriate of ammonia.

The nitrate of ammonia appears to exert a less energetic solvent action than the muriate.

Salts of Lead.-1. Carbonate of lead is clissolved in muriate of ammonia, especially when the solution of the ammoniacal salt is heated: when the carbonate is in small quantity it is dissolved without heat.

2. The oxide of the same metal is also dissolved, but it reguires a longer continuance of the heat.

3. The sulphate when in small quantity is dissolved without heat.

4. The oxalate is dissolved, especially in the warm ammoniacal salt. lution.

5. The tartrate and phosphate are dissolved in the cold so- 
6. The ferro-cyanate and chromate are not dissolved.

7. The iodide is dissolved even in the cold.

Salts of Zinc. -1. 'The carbonate is dissolved even in a cold solution of muriate of ammonia.

2. The phosphate undergoes solution in the hot salt, as does also the oxide.

3. The oxalate is soluble in a hot solution of muriate of anmonia.

4. The ferro-cyanate of zinc does not appear to dissolve.

The nitrate of ammonia is a somewhat less perfect solvent than the muriate.

Per-salts of Mercury.-1. The oxide is dissolved by a solution of muriate of anmonia, especially when heat is applied.

2. The triple salt produced by adding ammonia to a persalt of mercury is dissolved in the hot solution of the an moniacal salt.

3. The carbonate is dissolved by a hot solution of muriate of ammonia.

4. The phosphate and oxalate are dissolved in the cold solution of the ammoniacal salt.

5. The periodide is speedily dissolved in a lukewarm solution of muriate of ammonia.

6. The chromate is dissolved in the warm solution.

The nitrate of ammonia acts in the same way as the muriate.

Proto-salts of Mercury.-1. The sub-proto-nitrate does not nppear to undergo solution.

2. The black oxide undergoes solution.

3. The chloride, iodide, carbonate, phosphate, and tartrate dissolve in hot or warm muriate of ammonia, less completely, however, than the persalts.

Nitrate of ammonia is not so good a solvent as the muriate.

Proto-salts of Tron.-1. Neither the oxide, carbonate, phosphate, nor prussiate seems to undergo solution in muriate of ammonia or in the nitrate.

Per-salts of Iron.-1. The peroxide and its salts are similarly situated with the protosalts.

Salts of Antimony.-1. The protoxide dissolres in a cold solution of muriate of ammonia.

2. The carbonate dissolves in the hot solution.

3. The prussiate does not appear to suffer solution. The nitrate of ammonia acts in the same way as the muriate.

Salts of Silver.-1. Chloride of silver readily dissolves in hot muriate of ammonia, from which solution muriatic acid does not throw it down.

2. The carbonate undergoes solution in the hot salt.

3. The phosphate and oxalate undlérgo solution. Third Series. Vol. 10. No. 59. Feb. 1837. 
4. The prussiate does not appenr to undergo solution.

Nitrate of ammonia acts as a very imperfect solvent of the above salts.

Prolo-salts of Tin.-1. The oxidle appens to be only sparingly soluble in the hot as well as cold solution of muriate of ammonia.

2. The phosphate and prussiate do not appear to dissolve.

3. 'The oxalate dissolves readily' in a warm solution of muriate of ammonia.

The nitrate of ammonia appears to exert a solvent action only on the oxalate.

Per-salts of Tin.-1. Do not appear to undergo solution readily, if at all, either in the muriate or nitrate of ammonia.

Salts of Bismuth.-1. The oxide and carbonate undergo solution in muriate of ammonia.

2. The phosphate and sulunitrate readily dissolve.

The nitrate of ammonia exerts no appreciable solvent action over the above bismuthic salts.

Per-salts of Copper.-1. The oxide dissolves, as does also the carbonate, forming a fine deep-blue-coloured solution; if, however, the latter be acid, or heat be applied, a green-coloured solution of the chloride or subchloricle is formed.

2. 'The phosphate, oxalate, and prussiate do not dissolve.

Nitrate of ammonia does not dissolve the last three salts; it dissolves, however, the oxide and carbonate.

Salts of Manganese.-1. The oxide readily dissolves even in a cold solution of muriate of ammonia; not so the carbonate. When the solution of the oxide is heated it is not precipitated.

2. 'The phosphate is dissolved in the cold salt, but throws down a portion.

3. The prussiate is not dissolved.

The nitrate of ammonia dissolves the oxide in the cold, not so the carbonate. The phosphate is partially dissolved; heat however, causing it to come down again.

Salts of Cobalt.-1. The oxide is clissolved, even in a cold solution of muriate of ammonia, forming a pink solution; if, however the blue and hydrated oxide of cobalt be heated previously to the addition of muriate of ammonia, so as partially to convert it into a brown colour, the ammoniacal salt does not dissolve the brown portion of oxide.

2. The carbonate is dissolved even in the cold.

3. The phosphate undergoes a less perfect solution, and the prussiate does not dissolve.

If prussiate of potash, which produces a green precipitate in salts of cobalt, be added to a solution of such salts in mu- 
riate of ammonia, a yellowish brown-coloured precipitate ensues. The nitrate of ammonia acts much in the same way as the muriate.

Salts of Cadmium.-1. The oxide and carlonate dissolve in a cold solution of muriate of ammonia.

2. The phosphate and oxatate also dissolve in the cold fluid.

3. 'The prussiate does not undergo solution.

The nitrate of ammonia is a less perfect solvent of the salts of cadmium than the muriate.

Salts of Platinum.-1. The triple compound, chloride of platinum and potassium, is soluble in muriate of ammonia, as is also the chloride of platinum and ammonia.

None of the sulphurets of the preceding metals undergo solution in nuriate or nitrate of ammonia. In all the experiments the ammoniacal salts were added to the recently precipitated oxides and salts. The solution of phosphate of lime in muriate of ammonia may, however, be nearly if not entirely precipitated by an excess of caustic ammonia: if, on the contrary, only a small quantity of the caustic alkali be adkled, although a slight precipitate will take place and the fluid be slightly alkaline, still when filtered it will be found to contain lime by the addition of oxalate of ammonia. In the analysis, therefore, of a solution in muriatic acid supposed to contain phosphate and carbonate of lime, if sufficient ammonia be not added over and above that which is necessary to render the fluid somewhat alkaline, the filtered solution will be precipitated by oxalate of ammonia, and might lead to the supposition that carbonate of lime was present $:$ if even an excess of ammonia had been employed and the fluid heated, the same source of fallacy would exist, because the excess of ammonia would have been driven off, and the resulting fluid would contain phosphate of lime in solution; the same applies to the phosphate of baryta and stront:a, also to the phosphate of magnesia.

The salts of lead which are soluble in muriate of ammonia, are precipitated from that solution by an excess of calistic $\mathrm{am}$ menia: hence in precipitating solutions of lead by sulphuric or oxalic acil, where an ammoniacal salt exists, care should be taken that the fluid be strongly alkaline, so as to counteract the solvent power of the anmoniacal salt; the presence ot leal in such solutions would, however, be readily detected by sulphuretted hydrogen or hydro-sulphuret of ammonia. The fact of the oxides of iron not being soluble in muriate of ammonia might afford a means of separating them from several other metallic oxides with which they atre frequently united, more particularly the peroxide : by this means the latter might be separated from lead, nercury, antimony, zine, bismuth, 02 
copper, manganese. In certain cases, however, this would not be convenient unless the quantity of the above metals was inconsiderable. The oxides of manganese and cobalt, from their ready solubility, might easily be thus separated from iron.

R. H. BrETr.

XXII. Characters of a new Genus and some undescribed Specics of Araneidae. By JOHN BLACKWall, Esq., F.L.S., \& 8 . *

\section{Fribe, Inequitere, Latreille. Genus, Delctrix.}

$\mathrm{E}$ YES six in number, unequal in size, aggregated in pairs on the anterior part of the cephalothorax; two pairs are placed laterally, their anterior eyes being the largest, and their posterior ones the smallest of the six; the third pair is intermedfate, the eyes which constitute it heing oval, and contignous; the entire group forms two triangles united by the apices composed of the oval-shaped eyes.

Maxillæ enlarged at the base, cxterually, where the palpi are inserted, and slightly so at the extremity; inclined towards the lip.

1.ip short, triangular, and pointet.

Legs long, and moderately robust; the fourth pair is the longest, then the first, which a little exceeds the second in length, the third pair is the shortest. Tarsi triarticulate, the torminal joint being yery short and slender.

\section{Deletrix exilis.}

This minute spider has the cephalothorax oval, glossy, convex, pointea hefore, abruptly sloping behind. Mandibles slender, conical, vertical. Pectus broad, heart-shaped, convex, provided with some scattered hairs. 'These parts, with the maxillæ and lip, are pale red. Legs supplied with hairs, and with two rows of spines on the inferior surface of the tibia and tarsi, directed down the joints, those on the first and second pairs being the most conspicuons; they are of a pale yellowish brown colom, the thighs having a tinge of red. The palpi resemble the legs in colour, and are abundantly supplie.l with long hairs, particularly at the extremity. 'Tarsi triarticulate; the terminal juint, which is very short and slender, has two curved, pectinated ciaws at its extremity, and a small brush benenth them. Ahdomen oval, thinly covered with hair, projecting over the base of the cephalothorax; its colour is yellowish brown, with a band extending along each side of the medial line on the upper part, some irregular, oblique stripes on the sides, and a longitudinal band occupying the middle of the under part, of a browner bue. Plates of the spiracles pale yellow. Spinning mammulæ prominent, and of a pale yellowish white colour.

Length, from the anterior part of the cephalothorax to the extremity of the abdomen, $\frac{1}{6}$ th of an inch; length of the cephalothorax ${ }_{3}$; brealth

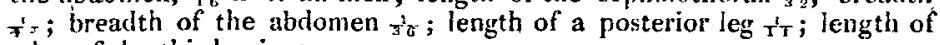
a leg of the third pair ty.

All the specimens of this spider which I have captured were females, and were discovered under stones and blocks of wood, at Crumpsall Hall, in September, 1836. Being ignorant of the cenomy of the species, I have placed it, provisionally, in the tribe Inequitcle, as it bears a close resemhimce to the spiders belonging to the genus Segtodes in the structure of the wouth.

* Communicated by the Author. 